\title{
La implantación de la escuela rural federal en Ixtlahuaca, México: una historia de desencuentros, 1924-1940
}

\author{
The Implementation of the Rural Federal School in \\ Ixtlahuaca, Mexico: a History of Disencounters
}

Celia Zarco González ${ }^{2}$

\begin{abstract}
Resumen
El objetivo de este artículo es explicar que las diferencias entre la escuela estatal y la escuela federal originaron contrariedades en los procesos de escolarización del distrito de Ixtlahuaca, México. Por ello, la Secretaria de Educación Pública (SEP) cambió su inicial radicalismo por la negociación, logrando así la institucionalización y expansión de la escuela rural federal al final del cardenismo. El estudio tiene una orientación de carácter histórico social y se ha fundamentado básicamente en archivos nacionales, estatales y municipales, además de documentos históricos.
\end{abstract}

Palabras clave: Contrariedades, escuela estatal, escuela rural federal, Ixtlahuaca.

\section{Abstract}

This article aims to explain the ways in which the differences between the State School and the Federal School caused setbacks in the schooling processes of the district of Ixtlahuaca, Mexico. Due to this situation, the Ministry of Public Education (SEP) had to change its initial radicalism for an attitude of negotiation, thus achieving the institutionalization and expansion of the Rural Federal School at the end of an historical period known as "Cardenismo". The present study has a social and historical orientation and has been basically based on national, state and municipal archives, as well as on historical documents.

Keywords: Setbacks, State School, Federal Rural School, Ixtlahuaca.

\footnotetext{
${ }^{1}$ Este artículo forma parte de los trabajos realizados durante los estudios de Doctorado en Ciencias de la Educación en el Instituto Superior de Ciencias de la Educación del Estado de México, ISCEEM.

${ }^{2}$ Celia Zarco González, Tesista del Doctorado en Ciencias de la Educación en el Instituto Superior de Ciencias de la Educación del Estado de México. Líneas de investigación: Los procesos de escolarización rural federal en el distrito de Ixtlahuaca, México, y la escolarización femenina durante la primera mitad del siglo XX en Ixtlahuaca, México. Correo electrónico: fabis417@yahoo.com.mx
} 


\section{Introducción}

Este artículo pretende explicar algunas contrariedades que tuvieron lugar entre comunidades con población mayoritariamente indígena - y, en menor medida, mestiza - que conformaban el distrito judicial y rentístico de Ixtlahuaca, México, entre 1924 y 1940 y el proyecto de la escuela rural federal. El distrito está conformado por cinco municipios: Ixtlahuaca, Jocotitlán y San Felipe del Progreso (con población mazahua) y Jiquipilco y San Bartolo Morelos (con habitantes otomís). El tiempo de estudio va de 1924 (año en que la Secretaría de Educación Pública hizo su entrada a la región) a 1940 (donde se marca el fin del gobierno cardenista), considerando que durante este segmento temporal la escuela rural federal logró su institucionalización y tuvo lugar el proceso de expansión del aparato escolar que la Federación impulsaba. El hilo conductor de esta historia son las diferencias entre la escuela estatal, que tradicionalmente había educado a los lugareños y cuya primera noticia que se tiene data de 1848 y la escuela rural federal, que arribó a la región en 1924 como parte de un "proyecto civilizador" apoyado en el binomio escuela-ejido.

Aunque la región ostentaba una importante tradición escolar estatal antes de que la Federación llegara, sólo se había escolarizado aproximadamente a un tercio de la población, puesto que la red escolar estatal contaba con más de 60 escuelas, mientras que la Federación fundó más de 100 escuelas entre 1924 y 1940 en el distrito judicial de Ixtlahuaca. Este distrito medía 1,744 km² y contaba con 178 localidades en 1897,3 mientras que para 1940 se registraron 257 comunidades. ${ }^{4}$ Por lo tanto, la política federal impulsó un proceso de escolarización compensatorio, ya que la mayoría de las escuelas fundadas tuvo lugar en comunidades que no habían tenido la experiencia de escolarizarse. No obstante, la Federación también fundó planteles en poblados que ya contaban con la escuela estatal, pero fueron menos; incluso se instalaron escuelas federales en las cabeceras municipales de Ixtlahuaca y Jocotitlán ${ }^{6}$ y, aunque la Secretaría de Educación Pública había celebrado un convenio ${ }^{7}$ con la entidad estatal

\footnotetext{
${ }^{3}$ Elaboración propia a partir del Censo de Villada (1902), ya que este documento incluye, en el distrito de Ixtlahuaca, a dos municipios que pasaron a formar parte del distrito de El Oro y excluye a un municipio que se anexó. Esta nueva división política tuvo lugar en 1901 y, para efectos de delimitar la zona de estudio, se han considerado los cortes enunciados.

${ }^{4}$ Elaboración propia a partir del Censo histórico de 1940 del Instituto Nacional de Estadística, Geografía e Informática (en adelante INEGI). Debido a que en este censo viene la suma de localidades de cada uno los municipios mexiquenses, ha sido necesario seleccionar los datos relativos a los municipios del distrito de Ixtlahuaca y sumarlos.

${ }^{5}$ Archivo Histórico de la Secretaría de Educación Pública (en adelante AHSEP), Año 1938, Ixtlahuaca, Estado de México, Dirección de Educación Primaria en los Estados y Territorios. Expediente 43 / 12376, Foja s/n.

${ }^{6}$ AHSEP, Año 1927, Jocotitlán, Estado de México, Dirección de Educación Primaria en los Estados y Territorios. Expediente 14/11705, Foja s/n.

${ }^{7}$ De acuerdo con Escalante, Alfonseca y Civera.
} 
en el que se especificaba que no fundaría escuelas en las cabeceras municipales, las instituciones citadas tuvieron la función de acotar el poder de algunas instancias locales.

Asimismo, las diferencias entre la escuela federal y la escuela estatal fueron consecuencia de que la Federación no reconoció la importancia de los saberes autóctonos, concentrando la atención en la implantación de su proyecto, muchas veces encarnado en autoridades que desconocían las necesidades reales de los pobladores de Ixtlahuaca porque habían sido formados con otra ideología. Tal es el caso de los inspectores federales que llegaron a la región, ya que ellos provenían de otros estados de la República, eran mestizos y su escolaridad era muy diferente a la de los profesores estatales y - en alguna medida - a la de los mismos mentores federales. Por ello:

La escolarización de masas fue un asunto público que ocupó la atención... en la transición del siglo XIX al XX... la instrucción rudimentaria de principios del siglo XX... propone que esta experiencia de escolarización preparó para una "ruptura relativa"... sobre quién es el pueblo y cómo educarlo entre finales del XIX y la escuela rural que despunta en la posrevolución. (Granja, 2010: s/d)

A pesar de las contrariedades suscitadas por este rompimiento, en el distrito de lxtlahuaca hubo diversas respuestas al nuevo proceso de escolarización. Algunas fueron de adhesión, pero la mayoría expresaron resistencia al cambio, ya que el problema no era sólo la introducción del nuevo modelo pedagógico que promovía la Federación, sino la pretensión de modificar el estilo de vida que se hallaba profundamente arraigado, cuyas instituciones no toleraban cuestionamientos.

\section{La escuela estatal}

Las primeras escuelas estatales de la región fueron fundadas a mediados del siglo XIX y, para fines del mismo, las cinco cabeceras municipales ya contaban con escuelas para niños y para niñas. El carácter unisexual de las mismas hacía notar el prestigio de las instituciones, ya que el profesor de la escuela para niños recibía un mejor salario que la profesora de la escuela para niñas. Sin embargo, también había escuelas estatales unisexuales en algunas comunidades con la categoría política de pueblos como Los Reyes, Santiago Yeché y San Miguel Tenoxtitlán del municipio de Jocotitlán (Escalante, 2008: 223-224).

La red de escuelas particulares se ha considerado para este estudio en conjunto con las escuelas estatales porque compartían la misma tira de materias, sin embargo, el origen del pago de sueldos era distinto ya que a los mentores de las escuelas particulares les pagaban los dueños de las haciendas. Aunque la mayoría de las escuelas particulares eran mixtas, 
también las había unisexuales como el caso de las escuelas ubicadas en la hacienda de Tiacaqué, en 1917, en donde la profesora percibía 80 centavos diarios y el profesor ganaba 95 centavos diarios. ${ }^{8}$

El plan de estudios de ambas redes escolares era semejante en cuanto a los saberes académicos, pero difería de acuerdo al sexo de los estudiantes. En la escuela para niños, las materias que se enseñaba eran lectura, escritura, gramática, cuentas, tablas de cuentas y doctrina cristiana. Para las niñas, las materias que se cursaban eran lectura, escritura, gramática, caligrafía, aritmética, bordados y doctrina cristiana. ${ }^{9}$

Como vemos, las diferencias entre las enseñanzas para cada uno de los sexos era que a los niños se les daban más clases de matemáticas que a las niñas y ellos no recibían materias propias de su sexo, como lo eran, para las niñas, las clases de bordado (que posteriormente se convirtieron en labores manuales).

La materia de doctrina cristiana se llamó, posteriormente, clase de Moral como efecto de la exigencia de una escuela libre de enseñanzas religiosas, aunque para lograr la laicidad de la educación aún faltaban muchos años, porque la escuela estatal conservó su tendencia religiosa aún durante el cardenismo, cuando se disfrazaba a la escuela confesional como escuela particular.

\section{La escuela federal}

Una de las deudas de la revolución, incluida en la Constitución de 1917, era la de educar al pueblo, lo que dio lugar a la creación de la SEP, en 1921, durante el gobierno del presidente Álvaro Obregón. El primer secretario de educación fue José Vasconcelos, quien consideró que se debería crear "una dependencia federal cuyas funciones civilizadoras, llegaran...a toda la República... El propósito fundamental... era la de salvar a los niños, educar a los jóvenes, redimir a los indios, ilustrar a todos y difundir una cultura generosa... de todos los hombres" (Ávila, 2015). Por ello, el "proyecto civilizador" que propuso la SEP, partió del concepto de que: "El México posrevolucionario está integrado por muchos Méxicos y en la tarea de identificarlos, la educación ha sido a lo largo del tiempo el instrumento que promueve la solidaridad entre ellos. Socializar para articular y conjugar nuestra heterogeneidad" (Herrera y Rodríguez, 1997: 4).

\footnotetext{
${ }^{8}$ Archivo Histórico del Estado de México (en adelante AHEM), Año 1917, Jocotitlán, Estado de México, Sección Escuelas Particulares, Expediente de la escuela particular de la Hacienda de Tiacaqué, Foja s/n.

${ }^{9}$ Archivo Municipal de San Felipe del Progreso (en adelante AMSFP), Año 1867, Ramo Educación, Expediente y foja s/d.
} 
Se pretendía integrar a los sujetos discriminados -ya fuesen indígenas o mestizos- en un México que se estaba reconstruyendo, por eso la SEP envió al campo a los maestros rurales, quienes serían los encargados de transformar a las comunidades, haciendo posible la tarea de: "Integrar al indígena al proyecto nacional, [que] significaba incorporar la civilización a nuestra cultura y no al contrario... dejar absorber a nuestra población india y mestiza marginada... por la vida económica en la civilización" (Herrera y Rodríguez, 1997: 4). La SEP dio a conocer su plan de trabajo a partir de 1923, cuya finalidad era la de formar a los nuevos ciudadanos de un pueblo civilizado, por lo que se consideró a la escuela como el centro de la vida de las comunidades, porque "la escuela y la educación tenían una función cotidiana: era un medio para el mejoramiento social y no sólo una actividad escolar...era práctica, acción; era aprender haciendo y su calidad respondía a la eficacia para alcanzar los fines sociales" (Herrera y Rodríguez, 1997: 5). De modo que "la nueva educación mexicana debía de ser algo propio de México, usando conceptos y un pasado histórico prohibido que reivindicaba un discurso tangente al de la posrevolución" (Silva, 2019).

La escuela rural federal pretendía modificar radicalmente el estilo de vida y, debido a ello, implementó diversas estrategias. Entre ellas, las relacionadas con el trabajo, como la formación de cooperativas de producción y de consumo y la introducción de los anexos escolares entre los cuales se podían contar los de carácter agrícola como el huerto, los semilleros y el cultivo de flores de ornato o los que criaban ganado menor, como aves de corral y conejos. La parcela escolar también contaba como anexo de la escuela, donde se pretendía que los alumnos aprendieran a trabajar y a administrar los recursos obtenidos.

Las campañas fueron un conjunto de estrategias utilizadas por la SEP, para las cuales se consideró que se debería aprovechar la disposición de las mujeres para entender lo que se les explicaba y la influencia que ellas podían ejercer sobre la familia. Entre ellas, se contaron las siguientes:

a) Pro árbol. Se trataba de cuidar los árboles, de cortar sólo lo que era indispensable, aunque hubo casos excepcionales como el que se vivió en San Bartolo Morelos, donde ante la "pobreza, las autoridades municipales solicitaron autorización para que los indios explotaran el monte de su propiedad haciendo menos dura su situación" (García, 1997: 89), pero sin fines de lucro, como podía ser la construcción de bancas para una escuela muy pobre que carecía de mobiliario. Para conservar la naturaleza se impulsaba la siembra y el cuidado de diversas especies, se destinaba un tiempo y lugar concreto para una ceremonia que intentaba despertar en los niños el amor por la naturaleza y, en los adultos, el respeto por la misma.

b) Higiénica. La escuela impulsó la práctica de hábitos de higiene personal como lavarse las manos y bañarse, para ello se utilizaron diversas estrategias que iban más allá de lo pedagógico, como lo informó la profesora de Chichilpa, San Felipe del Progreso: "procuré que los niños se asearan diariamente y que tomaran un baño se- 
manal. Para este objeto el día indicado obsequiaba a los alumnos que se bañaban la comida". 10

Mientras que, en San José Boqui, del municipio de Jocotitlán, se reportó que la maestra Julia Medrano confeccionó ropa para personas que nunca habían usado un vestido."

También se habló a las familias de la importancia de practicar el aseo del hogar, la limpieza de la cocina y la preparación de los alimentos, a no tener en la habitación a los animales, sino a destinarles un lugar específico. Además, se vacunó a los adultos y a los niños, ya que la mortandad infantil era mayor al 50\%. Se combatieron epidemias como el tifo y la viruela. Los mismos inspectores llevaban las vacunas y el polvo de haba para secar las erupciones cutáneas originadas por las enfermedades. Asimismo, se prohibieron las misas de cuerpo presente para dar el último sacramento a los difuntos, ya que el templo era un espacio donde los asistentes se podían contagiar:

c) Desfanatizadora. Algunos pobladores de la región no acataban la ley sobre la reglamentación de cultos y, para ello, utilizaban tácticas que les permitían evadirla; por su parte, los inspectores federales los combatieron y los denunciaron, como lo denota la siguiente cita: "se trasladaron depósitos sagrados de una capilla a otra, lo que se hace a pesar de las disposiciones legales, revelan el atraso de estas gentes y su fanatismo". 12

Mientras tanto, el clero mantenía una campaña contra la escuela federal, predicando desde el púlpito para que los padres no mandasen a sus hijos a la escuela mixta, ya que argumentaban que se estaba corrompiendo la inocencia de los menores..$^{13}$ Además de estar juntos niños y niñas, se les daba clases de educación sexual. Debido a estas afirmaciones, disminuía la asistencia a la escuela, pero luego se recuperaba porque los inspectores visitaban casa por casa persuadiendo a los padres de familia para que mandaran a los niños a la escuela, e informándoles que, si no los enviaban, se harían acreedores a una multa que el gobierno les impondría porque la educación era obligatoria:

d) Antialcohólica. La SEP utilizó determinados recursos para combatir el alcoholismo, entre ellos estaban las pláticas que los inspectores hacían con los vecinos, explicando las consecuencias que este proceder ocasionaba a la salud, además de la reducción

${ }^{10}$ AHSEP, Año 1943, San Felipe del Progreso, Estado de México, Dirección de Educación Primaria en los Estados y Territorios, Expediente 12 / 12052, Foja s/n.

${ }^{11}$ AHSEP, Año 1931, Jocotitlán, Estado de México, Dirección de Educación Primaria en los Estados y Territorios, Expediente 2 / 11908, Foja s/n.

12 AHSEP, Año 1931, Ixtlahuaca, Estado de México, Dirección de Educación Primaria en los Estados y Territorios, Expediente 6/ 11749

${ }^{13}$ AHEM, Año 1934, Ixtlahuaca, Dirección de Educación Pública. Escuelas Particulares, Volumen 8, Expediente s/n. 
del gasto familiar. Como lo informó el inspector federal Rafael Sánchez, en 1932, con respecto a San Bartolo Oxtotitlán del municipio de Jiquipilco: "Hice conversaciones con los vecinos sobre el consumo del alcohol y sus efectos sobre el individuo como en la familia, especialmente en la herencia". ${ }^{14}$

En la revista El Maestro Rural, se publicaban carteles alusivos a las consecuencias del alcoholismo. El inspector Rafael Sánchez mostró algunas de estas imágenes a los pobladores de San Ildefonso, del municipio de Ixtlahuaca, "consiguiendo causar una fuerte impresión de dolor sobre el estado en que se encuentran los alcohólicos y la fatal herencia que dejan a sus hijos". ${ }^{15}$ Se intentaba que las mujeres convencieran a sus esposos para que abandonaran esta práctica. Por su parte, los pobladores argumentaban que la ingesta de pulque era ocasionada por la insuficiencia del vital líquido, asunto que fue reportado por el inspector federal José Alcázar Robledo refiriéndose a Santa María Citendejé, del municipio de Jocotitlán: "No hay agua para los usos domésticos, las indias viajan más de cinco kilómetros para traer agua, en consecuencia no tenemos jardín ni hortaliza". ${ }^{16}$

No obstante, el inspector Alcázar Robledo solicitó ayuda a las autoridades para que prohibieran la venta de este tipo de bebidas: "pedí....al Presidente Municipal que imponga su autoridad... [ya que] aquí, por fortuna no hay magueyales, pero hay muchos vendedores de pulque" (AHSEP).

La respuesta de las comunidades al ejercicio de las campañas fue diversa. Hubo desde la aceptación hasta el rechazo total, o el procedimiento de acatar, pero no de cumplir. En general, fue de no aceptación porque los pobladores consideraban que la escuela federal no les debería enseñar asuntos de la vida cotidiana o del trabajo, sino que se debía encargar de los conocimientos académicos, tal y como lo venía haciendo la escuela estatal.

Como vemos, los postulados de la escuela rural federal chocaban con las costumbres y tradiciones de los pueblos, y también con los preceptos que dictaba la escuela estatal. Por ello, hubo diversos desencuentros que afectaron de una u otra forma el desarrollo del proyecto que la Federación impulsaba; entre los desencuentros pueden citarse básicamente los de carácter religioso y agrario.

\footnotetext{
${ }^{14}$ AHSEP, Año 1932, Jiquipilco, Estado de México, Dirección de Educación Primaria en los Estados y Territorios. Expediente 14 / 11703.

${ }^{15}$ AHSEP, Año 1931, Ixtlahuaca Estado de México, Dirección de Educación Primaria en los Estados y Territorios. Expediente 43 / 111679.

${ }^{16}$ AHSEP, Año 1932, Jocotitlán, Estado de México, Dirección de Educación Primaria en los Estados y Territorios. Expediente 14 / 11722.
} 


\section{Contrariedades de origen religioso}

En este periodo de estudio (1924-1940) se presentaron dos conflictos religiosos entre el pueblo y el estado, Ilamados Cristiadas, en los cuales el clero abanderó al pueblo para que arremetiera contra el gobierno federal. El primer movimiento tuvo lugar entre 1926 y 1929 a consecuencia de la promulgación de la llamada Ley Calles, "que creaba una serie de delitos en relación con el culto, educación y prensa religiosos" (Yhmoff, 1979: 149).

El movimiento cristero fue un conflicto de gran envergadura porque tocó a la mayoría de los estratos sociales, ya que por diversas razones vieron perjudicados sus intereses, puesto que: "La lucha de poder entre Iglesia y Estado fue generando...enfrentamientos y la división fue haciéndose cada vez más amplia... ningún enfrentamiento fue más participativo y más sangriento, que la Guerra Cristera, donde un pueblo de creyentes fue coaccionado a luchar" (Silva, 2014: 79). Lo que al inicio sólo parecía un problema entre el gobierno y la iglesia tuvo mayores alcances, ya que "el anticlericalismo, con mayor sesgo ideológico, se convirtió en otra bandera revolucionaria, junto al reparto agrario y a otras reivindicaciones obreristas" (Olivera, 1987: 19). Todas estas demandas, que fueron motor de la Revolución, aún se hallaban pendientes de una solución y encontraron en esta discrepancia una oportunidad propicia para expresar el descontento contenido. Muchos miembros del ejército revolucionario eran, al mismo tiempo, campesinos y católicos agraviados; además, su esfuerzo en la guerra no se había reconocido y esto se sumó a que no se les entregó la tierra. Ahora, para colmo, se ponía en riesgo su fe, porque "La sociedad católica sintió amenazadas sus más profundas creencias, y la lucha del pueblo católico mexicano, contra el gobierno anticlerical de Calles, fue por defender lo más sagrado para los católicos, su fe (Silva, 2014: 79).

En la región de estudio, no hubo hechos sangrientos por motivo de la Cristiada "ya que mientras en buena parte del país, los católicos decidieron defender por las armas a la iglesia perseguida, en San Felipe del Progreso se concretaron a proteger pacíficamente a los sacerdotes" (Yhmoff, 1979: 149). Sin embargo, si apoyaron al movimiento cristero: "Doña Teresa Caballero, vecina de Tapaxco [que] era militante de las brigadas femeninas, y recorría el pueblo solicitando balas y armas para entregarlas personalmente a los cristeros" (Yhmoff, 1979: 152).

Los arreglos a los que habían llegado la iglesia y el gobierno al final de la primera Cristiada tuvieron un carácter verbal, ya que era ilegal escribirlos debido a que la constitución prohibía la negociación. Se tenía que cumplir la ley. En ellos, se muestra que, para la iglesia, la situación ya era insostenible y que el gobierno no cedió en la aplicación de los preceptos promulgados, pero ofreció aplicarlos "sin tendencia sectarista" (Olivera, 1987: 216). Por su parte, el clero continuó el ataque contra la escuela rural federal; aunque: "Con estos acuerdos el Estado había demostrado su capacidad para concertar alianzas y, también, lo efectivo de 
su maquinaria represora para someter a eventuales enemigos" (Olivera, 1987: 19). Sin embargo, la ofensiva clerical ocasionaba la disminución de la asistencia a la escuela, luego los maestros e inspectores volvían a hacer campaña para que los padres enviaran a sus hijos a la escuela y aumentaba la asistencia, por ello puede leerse un régimen con crestas y valles en los registros de asistencia que elaboraban los inspectores para informar de sus visitas en algunas escuelas. Empero, estas diferencias también obedecían a la experiencia de escolarización que las comunidades habían tenido anteriormente.

Por ejemplo, tenemos el caso del pueblo de San Gregorio Macapexco del municipio de San Bartolo Morelos. Este pueblo contaba con una escuela estatal desde $1902^{17}$ y, en 1927, se fundó una escuela rural federal cuya construcción avanzaba lentamente, ya que los padres argumentaban que no tenían dinero para edificarla. Sin embargo, ofrecieron pagar al sacerdote del lugar para que les ayudara en las pruebas finales, ${ }^{18}$ lo que, en realidad, significa que el pueblo practicaba el tortuguismo ${ }^{19}$ como una estrategia para boicotear a la escuela federal. Mientras tanto, la iglesia continuaba - desde el púlpito - el combate contra la escuela.

No conforme con ello, el presbítero de Morelos hizo dos visitas al plantel en 1932, las cuales fueron reportadas por la Srita. Profesora María de Jesús Rodarte al inspector J. Buenaventura García, quien a su vez envió una carta al Presidente municipal para que reconviniera al sacerdote a respetar a la escuela federal (AMSBM).

En el informe de la profesora, puede leerse que el cura hizo una de las visitas en calidad de inspector, que cuestionó a los niños y que se enojó porque no quisieron leer, además de que les ordenó que pasaran a la misa. La maestra anotó: "A mi [sic] me cayó mal esa orden porque no es particular mi escuela y creo que estoy enteramente independiente" (AMSBM). Esta nota permite ver que el sacerdote consideraba que su poder sobre las conciencias también podía ejercerse en la escuela federal y, como no quería perder la plaza de ese pueblo, ofreció - a cambio de la lealtad de los feligreses - sus servicios para ayudar a los niños en sus exámenes finales.

Es de notarse que el nivel de analfabetismo de las comunidades de San Bartolo Morelos era de los más bajos del distrito de Ixtlahuaca, a pesar de que, desde el Porfiriato, se venía clasificando a Morelos como uno de los municipios más pobres - además de ser el lugar donde menos escuelas federales se establecieron. En otras palabras, los pobladores de San

${ }^{17}$ Archivo Municipal de San Bartolo Morelos (en adelante AMSBM), Año 1902, Ramo Educación. Expediente s/n.

${ }^{18}$ AMSBM, Año 1932, Ramo Educación. Expediente s/n.

${ }^{19}$ Esto hace referencia al hecho de actuar con lentitud como una forma de mitigar la opresión. Vaughan, Mary (2002), "La Historia de la educación y las regiones en México: cómo leer los informes de los inspectores escolares". En: Civera, Alicia; Escalante Carlos y Galván, Luz Elena (coord.). Debates y desafíos de la historia de la educación en México. Zinacantepec, Estado de México, El Colegio Mexiquense, A.C.; Instituto Superior de Ciencias de la Educación del Estado de México, p. 45. 
Bartolo Morelos estaban interesados en escolarizarse, pero básicamente fueron alfabetizados por la escuela estatal.

La segunda Cristiada, acaecida entre 1934 y 1938, se desencadenó con el grito de Guadalajara, mediante el cual Plutarco Elías Calles se pronunció por impulsar el carácter laico y científico de la educación. Esto llevó al régimen a la promulgación de la educación socialista que proponía la enseñanza basada en los saberes exactos y racionales, y conservaban las reformas de Bassols sobre la coeducación y la educación sexual. Aunque el clero condenó la lucha armada, prohibió a los padres que enviaran a sus hijos a la escuela so pena de excomunión; mientras tanto, el gobierno amenazó con prisión y multas a los padres que no mandaran a la escuela a sus hijos, aludiendo a la obligatoriedad de la educación. Esta reforma a la educación era un fuerte golpe para la oferta educativa religiosa, ya que enunciaba que: "La educación dada por el Estado será socialista, y no contenta con excluir toda doctrina religiosa, combatirá el fanatismo y los prejuicios" (Meyer, 1989: 12). Por ello, la iglesia católica hizo circular volantes que daban a conocer al pueblo su posición con respecto a la nueva ley sobre la educación; la respuesta de los padres de familia, en general, fue la de no enviar a sus hijos a la escuela. En consecuencia, el gobierno tuvo que reconsiderar su inicial postura y fue disminuyendo su radicalismo.

Durante la implantación de la educación socialista, en el Estado de México los problemas con la escuela fueron relativos ya que el gobierno era de tendencia moderada y, el Director de Educación Federal, Eduardo Zarza, recomendó que la labor educativa se desempeñara con prudencia y tolerancia para no poner en riesgo la vida del personal docente. ${ }^{20}$

Sin embargo, en 1937, cuando la gubernatura mexiquense fue tomada por Wenceslao Labra y la Dirección de Educación Federal del Estado de México estuvo encabezada por el profesor Septimio Pérez Palacios, se suscitaron problemas relacionados con la escuela porque el nuevo director de educación se distinguió por ser un radical marxista. Las instancias locales de poder como la iglesia y los caciques no estaban dispuestas a ceder terreno, por lo que el general Labra solicitó al presidente Cárdenas la destitución del profesor Septimio Pérez, argumentando lo siguiente: "Por causas que personalmente comunicaré a usted, suplícole dé sus respetables órdenes para que el Director Federal de Educación de este Estado sea removido y poder así comenzar año escolar próximo con mayores ventajas para educación pueblo de mi Estado" (AHSEP).

El Director Federal de Educación recibió apoyo de los maestros federales de Ixtlahuaca y de otros lugares del país, así como de los obreros y de los transportistas, entre otros gremios, quienes firmaron un telegrama enviado por el profesor Filiberto Mondragón con el siguiente texto: "Sr. Presidente, pedimos ayuda para que no sea removido el Director de Educación

${ }^{20}$ AHSEP, Año 1937 Informe de Eduardo Zarza, Director de Educación Federal en el Estado de México. Caja IV Expediente 100(04) (IV-5) (725.4)/1 
Federal."21 Sin embargo, como dicha solicitud no fue aceptada, en 1939 se nombró al Profesor Martín González Vázquez como Director de Educación Federal.

Durante la administración del profesor Septimio Pérez, se presentaron en la región dos conflictos inducidos por el radicalismo de las autoridades educativas. El primer conflicto tuvo lugar en 1937 en Atlacomulco, municipio que no forma parte del distrito de Ixtlahuaca pero que tiene frontera con cuatro de los cinco municipios de la región. Debido a que algunas de las gestiones de los maestros federales incomodaron al cacicazgo regional, un mentor fue asesinado y los causantes huyeron a San Felipe, por lo que se consideró que corría riesgo la vida de los otros maestros federales. Debido a esto, el inspector de Atlacomulco y de San Felipe del Progreso, el profesor José Ventura García, solicitó al profesor Septimio Pérez, diez máuseres para la protección de él y de los demás preceptores.22

El otro caso, que ocurrió en la cabecera de San Felipe del Progreso, muestra la tendencia radical del profesor Pérez Palacios al exigir que la Escuela Particular Mixta y Superior "Coronel Filiberto Gómez", encabezada por el profesor Alfonso Novia Luja, se ciñera estrictamente a los lineamientos establecidos por la SEP. Los padres de familia que enviaban a esta escuela a sus hijos se oponían a la educación sexual y a la coeducación, aunque la escuela ostentaba el nombre de mixta. Los tutores objetaban que deseaban conservar la "virtud de la niñez". En esta lucha, los diversos actores de la educación implementaron estrategias para defender su posición.

El conflicto se inició en enero de 1934, cuando se informó al gobernador que la escuela particular, además de ser Mixta, era Superior. Para verificarlo, se envió al Inspector Juan Avilés el día nueve de junio de ese año, quien manifestó lo siguiente: "teniendo únicamente dos maestros, los que no pueden atender a seis cursos...por los intereses sociales, me permito suplicar atentamente a usted que dicha escuela sea clasificada de acuerdo con el personal de que dispone" 23

En consecuencia, el responsable de la Secretaría mandó una carta al presidente municipal, donde se otorgaba el plazo de un mes para que cada grado tuviera un profesor; de lo contrario, la escuela se clasificaría como rural, a lo que el profesor Novia contestó que comprendía las exigencias, por lo que haría lo posible por contratar un profesor auxiliar, pero no se nombraría más personal porque eran pocos niños por cada curso. Por su parte, el gobierno mexiquense exigió que se contratara prontamente al profesor; para el 18 de octubre de ese año, ya se había nombrado al mentor (AHEM).

\footnotetext{
${ }^{21}$ Archivo General de la Nación (en adelante AGN), Año 1938, Grupo documental Cárdenas, Expediente. 534.6-722.

22 AHSEP, Año 1937, San Felipe del Progreso, Estado de México, Dirección de Educación Primaria en los Estados y Territorios. Caja 3402 Expediente IV/130 (725.4) Foja s/n.

${ }^{23}$ AHEM, Año 1934 Dirección de Educación Pública. Escuelas Particulares, Volumen 8, Expediente s/n.
} 
Como vemos, las recomendaciones del inspector no se respetaron. En vez de aplicar la ley, tuvo lugar la negociación y la escuela siguió funcionando como de costumbre. Sin embargo, El 29 de marzo de 1937, cuando el puesto de Director de Educación Federal en el Estado de México fue ocupado por el profesor Septimio Pérez Palacios, se volvió a revisar la situación de la escuela y se envió un escrito al presidente municipal, expresándole lo siguiente:

Sabemos que está funcionando en ese lugar una escuela Particular que dirige el $C$. Alfonso Novia Luja. [No] puede funcionar en su condición de particular sin incorporarse, llenando todos los requisitos...que el Art. $3^{\circ}$. Constitucional establece. Esperamos que a vuelta de correo nos envie [sic] el acta de clausura... y tome las medidas necesarias para que no funcione clandestinamente. ${ }^{24}$

Se marcó copia de este oficio al Gobernador Constitucional del Estado donde se le decía: "suplicándole que conforme a su acuerdo verbal rectifique esta orden al C. Pte. Mpal, a quien nos dirigimos, haciéndole notar que ni en la cabecera, ni en otros lugares deben funcionar escuelas particulares sin que estén debidamente autorizadas" (AHEM). Este exhorto fue ratificado por el ejecutivo mexiquense al alcalde, informándole al profesor Pérez Palacios que ya se había cumplido su disposición.

El C. Rodolfo Salgado, presidente municipal, informó que la escuela ya no era particular sino nocturna y era sostenida por el gobierno municipal para atender a los hijos de los campesinos que tenían más edad de la considerada para asistir a la escuela de los niños. Debido a que no se efectuó la clausura indicada, el director de Educación Federal envió dos telegramas. En el primero, se le indicaba al inspector federal Sócrates Castellanos que verificara el cumplimiento de la orden; en el segundo telegrama, se solicitaba al gobernador que investigara discretamente lo informado por el alcalde de San Felipe del Progreso (AHEM).

Por su parte, las madres de familia de la cabecera municipal organizaron una reunión para celebrar su día y expresar su desacuerdo con la coeducación y la educación sexual, ya que las consideraban contrarias a las buenas costumbres, argumentando:

que estando estos niños rodeados de peligros y expuestos a que pierdan sus virtudes ya con las malas compañías y muy especialmente con las malas enseñanzas que actualmente los rodean...era necesario se formara una unión de madres de familia, que exclusivamente se dedique a velar por los intereses de sus hijos vigilando por los principios de buena educación (AHEM).

Más allá, se designó a la mesa directiva y se determinó afiliarse a la Confederación de "Unión de Padres de Familia" que existía en la Ciudad de México (AHEM). De acuerdo a esta

${ }^{24}$ AHEM, Año 1937, Dirección de Educación Pública. Escuelas Particulares Volumen 9, Expediente s/n. 
nota, las madres de familia eran letradas y sabían lo que pasaba en la capital; con esta afiliación se constituyeron formalmente en partícipes del movimiento contra la escuela federal.

Entre tanto, el Receptor de Rentas del Estado, tras realizar la investigación requerida, envió un mensaje el 22 de mayo al Secretario General de Gobierno informándole que el profesor Novia, además de atender su tienda, daba clases (en un horario diferente al escolar), a los trabajadores de la raíz de zacatón y a otros alumnos que le daban un pago extra, ya que la presidencia le abonaba $\$ 50.00$ mensuales por este concepto (AHEM). De modo que, el 23 de junio de 1937, el profesor Septimio Pérez envió al profesor Novia una nueva notificación para que incorporara su escuela al sistema y evitara así la clausura. A esto, el profesor respondió que atendía el curso superior porque los padres de los niños "le rogaron", ya que, de lo contrario, los niños no podrían terminar la educación primaria porque no se contaba con ese nivel de estudios en la comunidad. El director de Educación Federal manifestó que se clausurara la escuela, mientras no se apegase al reglamento. El 15 de julio, el inspector federal giró un oficio al profesor Novia con la misma exigencia y un fragmento del Reglamento de Escuelas Particulares que decía: "La educación... será socialista y además de excluir toda creencia religiosa, combatirá el fanatismo y los prejuicios" (AHEM). Además, agregó que los profesores oficiales del lugar afirmaban que: "la mayor parte de la población infantil la viene controlando usted" (AHEM). Por ello, se otorgó un nuevo plazo de cinco días para la incorporación de la escuela, o se clausuraría.

Mientras tanto, la mesa directiva de la unión de madres de familia comunicó el cuatro de agosto de 1937 a la profesora María de la Luz Rodríguez, directora de la escuela mixta "Elena Morales", que los vecinos no mandarían a sus hijos a la escuela oficial con la siguiente nota:

No tratan de poner obstáculo, por ningún motivo, a la educación impartida por el Supremo Gobierno al que están sumamente agradecidas, pero no consentirán [sic], jamás que se les enseñe a los niños cosas completamente contrarias a la razón y a la moral (AHEM).

Sin embargo, la pronunciación de las madres de familia no logró que la Federación cediera en su empeño de exigir que se escolarizara juntos a niños y niñas, por lo que el 24 de agosto se verificó una reunión de padres de familia en la escuela mixta para formar el Comité de Educación que se integró de la siguiente manera: Francisco J. Téllez, presidente; María de la Luz, secretaria; Laura M. de Castro, tesorera; Ernesto López Soriano, primer vocal, Asunción R. de Castro, segunda vocal (como vemos, la tesorera y la segunda vocal del Comité eran respectivamente la Presidenta y la Secretaria de la Mesa Directiva de la Unión de 
Madres de Familia); el profesor Alfonso Novia también formaba parte de este comité, pero no se mencionó su cargo (AHEM).

El inspector federal, José Ventura González, envió al Gobernador un oficio el dos de septiembre de 1937, dándole a conocer que con la labor de la profesora Luz Rodríguez la escuela funcionaba con cierto consenso. Sin embargo, ante la nueva administración de la profesora Casilda Blanco - cuya tendencia era revolucionaria - los vecinos pudientes, secundados por el cura, presionaron a la profesora para que dejara la escuela. La Federación aceptó, a cambio de que la escuela fuese mixta; más allá, dejó en manos del alcalde la responsabilidad de hacer cumplir el carácter socialista de la educación, argumentando que: "niños y niñas han quedado en un sólo plano educacional, libres de prejuicios que tanta preocupación causa todavía a los cerebros ancianos" (AHEM).

Por su parte, el inspector formuló dos consignas: a) Que se clausurara inmediatamente la escuela de niñas y b) que pasaran a la Escuela Mixta Oficial sin miramientos, contrastando el censo escolar con la inscripción para que se sancionara a los padres de familia que no mandaran a sus hijos a la escuela (AHEM).

El inspector José Ventura González dirigió un oficio al Gobernador el seis de septiembre, donde le informaba que en la escuela oficial se había formado el Comité de Educación, en su "acta...se puede apreciar, todavía el resto de resistencia que presentaron elementos contrarios a la enseñanza socialista [como lo muestra el comentario de] El Sr. José Yhmoff, [quien] tomó la palabra para exponer que (algunos padres de familia) no estaban conformes con la fusión de la escuela...; a lo cual, le contestó el señor J. Téllez que debía ser Mixta como eran todas las de la República y que además eran disposiciones superiores, pero después de una acertada discusión fue aceptada la doctrina revolucionaria de la coeducación". ${ }^{25}$ Sin embargo, aún quedaba pendiente la clausura de "la escuela parroquial con disfraz de particular a cargo del profesor Alfonso Novia Luja" (AHEM), pidiendo al gobernador que nuevamente ordenara al presidente municipal el cierre del plantel y enviara al inspector una copia del censo de los niños que pasarían a la Escuela Oficial.

Después de todos estos trámites, el 17 de septiembre el profesor Septimio Pérez Palacios envió un oficio al Gobernador donde le indicaba que clausurara la escuela, por lo que el Secretario General de Gobierno, el Lic. Juan Fernández Albarrán, mandó un escrito al maestro Alfonso Novia "recomendándole" que cerrara la escuela. El presidente municipal y el inspector federal, José Ventura González, vigilarían que la orden se cumpliera. En la última página de este expediente puede leerse un escrito del Director de Educación Federal dirigido al Lic. Juan Fernández Albarrán donde se le informa que ha tenido conocimiento de la consigna enviada al profesor Novia Luja fechada el seis de octubre (AHEM). No obstante que

${ }^{25}$ AHEM, Año 1937, San Felipe del Progreso, Dirección de Educación Pública Escuelas Particulares. Volumen 9. 
no se logró encontrar el acta de la clausura de la escuela, consideramos que ésta tuvo lugar después de tres años y muchas gestiones por parte de las autoridades federales, quienes se opusieron al funcionamiento de la escuela particular ubicada en la cabecera municipal porque no respetaba los lineamientos de la SEP.

\section{Contrariedades de origen agrario}

La Federación impulsaba un "proyecto civilizador" de carácter integral, que pretendía transformar, en todo sentido, la vida de la comunidad colocando en el centro a la escuela rural federal. Por ello, se integró el binomio escuela-ejido, según el cual a las comunidades se les dotaría de tierras y aguas para convertirlas en entidades productivas y se fundaría una escuela que los enseñaría a trabajar, aparte de alfabetizarlos, para así poder integrar a todos los individuos como ciudadanos de una nación emancipada.

Se pretendía lograr una revolución cultural posterior a la lucha armada, para que se hicieran a un lado las diferencias étnicas y se tuviese un nuevo indio mexicano que fuese libre del capitalismo nacional y extranjero (Palacios, 1999: 33). Por ello, la SEP desplegó, sobre las comunidades rurales, su aparato escolar encarnado en las personas de los maestros rurales, quienes hacían trabajo de todo tipo, como enseñar el idioma español, lectura, escritura y nociones de cálculo. Más allá, instruían acerca de las labores femeniles, tales como costura, cocina, e higiene de la casa y de la ropa. En el caso de los profesores, se hacían acompañar de su esposa o de su hermana para que se encargara de estas materias; generalmente, estas mujeres no recibían pago porque carecían de nombramiento. Para los varones, se implementaban talleres con los recursos con los que la zona contara, por ejemplo: carpintería, curtiduría y herrería. Entre las actividades de carácter recreativo que se incluyeron para todos los habitantes, pueden contarse funciones de teatro al aire libre, sesiones de canto y guitarra, así como juegos de futbol y basquetbol.

Otros personajes que formaron el equipo de la SEP fueron los inspectores federales, quienes hacían visitas didácticas a las escuelas, daban clases de demostración de las materias académicas, organizaban las actividades relativas a la parcela escolar, exhortaban a los padres de familia para que enviaran a sus hijos a la escuela, llevaban las vacunas y daban aviso para el control de las epidemias; trazaban pozos y caminos vecinales y hacían compras para la escuela - como balones, utensilios de cocina, herramientas, medicamentos, enseres de limpieza y otras cosas. Además de esto, respaldaban a los maestros para defenderse de los ataques de la iglesia y de los antiagraristas.

Por su parte, el Director de Educación Federal en el Estado de México también hacía presencia en las comunidades - aunque con poca frecuencia. En sus informes, puede leerse 
que recorrían muchas localidades de esta zona, describiendo geográficamente al lugar, las condiciones de vida, la situación de la escuela federal y los trabajos que realizaban los inspectores. Su labor, más que de gestión, era de orientación acerca de cómo deberían conducirse los maestros y los inspectores federales. Algunos de estos directores eran radicales y consideraban que el "proyecto civilizador" de la SEP debía aplicarse al pie de la letra, lo que trajo consigo la baja en la asistencia y expresiones de rechazo a los preceptos en viados por la Federación. Sin embargo, gradualmente se fue modificando esta postura, tornándose más conciliadora; por ello, se cambió la exigencia por la negociación, una suerte de intercambio en el que la Federación dotaba con tierras y aguas a las comunidades y éstas respondían aceptando y apoyando a la escuela federal.

Mientras que la mayoría de los maestros estatales no respetó las líneas de trabajo que marcaba la SEP, conservando su antigua forma de enseñar, tampoco hizo suyas las preocupaciones de los campesinos que solicitaban la dotación ejidal y que veían en el maestro federal a un apóstol que generalmente sabía de todo lo que preguntaban y se mostraba solícito para ayudarles a leer y escribir una serie de documentos que les imponía su condición de ejidatarios.

En cuanto al reparto agrario, Jocotitlán sobresalió en la región por sus problemas. El caso de Santiago Yeché resulta ilustrativo y, aunque su dato no aparece en el catálogo que documenta el reparto agrario, es claro que le fue otorgada una dotación, incluyendo a la escuela que recibió cuatro hectáreas en $1928 .{ }^{26}$ En este pueblo se vivieron graves conflictos. El inspector federal José Alcázar Robledo los documentó explicando que:

Este vecindario está colocado en una situación verdaderamente dolorosa: Los mestizos, son antiagraristas y enemigos mortales de los pobres indios que han aceptado el agrarismo como salvación económica... No se puede hacer nada en este momento, pues no hace mucho tiempo que pelearon los mestizos con los indios y hubo muchos muertos (AHSEP).

Como vemos, las consecuencias negativas para la escuela no se hicieron esperar puesto que: "Los mestizos están adueñados de los terrenos planos y los indios tuvieron que irse a vivir a las lomas o al cerro. Precisamente a eso obedece que no haya Grado Preparatorio, pues en la escuela no hay un solo indio" (AHSEP).

Con la lectura de estos hechos puede verse que en Santiago Yeché, como en otros pueblos; la pretensión de la Federación de dotar de ejido a las comunidades y de formar una bina con la escuela federal, no obtuvo la respuesta que se esperaba. Se tenía el propósito de lograr

${ }^{26}$ AHSEP, Año 1928, Jocotitlán, Estado de México, Dirección de Educación Primaria en los Estados y Territorios. Expediente 6 / 11748. 
que el reparto pusiera fin a las ancestrales disputas por la tenencia de la tierra, asignando a los campesinos una fuente de trabajo que fuese viable y les permitiese obtener lo necesario para vivir, aprovechando las enseñanzas que la escuela les ofrecía.

Asimismo, se presentaron conflictos directos con la tenencia de la parcela escolar, como lo señaló el inspector Rafael Sánchez el 24 de marzo de 1934, dado que el presidente del comité agrario: "procedió a [repartir]... fracciones del ejido escolar [por lo que] inicié... gestiones [para] lograr que se respetara el derecho de la Escuela sobre el terreno que en la dotación se le había entregado... obteniendo... que se devolviera ... el terreno" (AHSEP). A pesar de la legalidad de la parcela escolar, el representante local agrario consideró que tenía autoridad para repartir una propiedad federal, contrariando no sólo a la SEP, sino también a la Comisión Agraria.

De igual forma, se presentaron problemas en torno al hecho de trabajar la parcela escolar como lo informó, en 1936, el maestro del Fresno Niche, José Guadalupe Rodríguez: "Se sembró la parcela escolar...a base de sacrificios, pues los vecinos no querían cooperar debido a las influencias del cura, pero esta escuela se puso en el lugar que le correspondió, gracias a ello se pudo hacer algo" ${ }^{27}$ Con esta nota, vemos que la escuela tenía que luchar con diferentes instancias de poder que obstaculizaban el desarrollo del proyecto impulsado por la Federación.

\section{Conclusiones}

La primera Cristiada fue un movimiento de la iglesia contra el gobierno, en el que el clero arengó al pueblo a lanzarse a la lucha armada. El móvil fue suspender el culto, en vez de reducirlo como lo planteaba la ley, pues el pueblo podía tolerar que hubiese pocos sacerdotes que administraran el culto, pero no soportaba quedarse sin la atención religiosa que ya se había convertido en una necesidad. Por ello, las consecuencias directas contra la escuela federal giraron en torno al desprestigio de la misma; a la lucha por los espacios físicos (cuando la Federación tomó los templos y sus anexos y los acondicionó para que funcionaran como escuelas) y a la contienda por conservar el dominio de las conciencias y así asegurar el control de los recursos que la iglesia obtenía al ofrecer servicios educativos con el carácter "moral" del que carecía la escuela federal. En tanto que la segunda Cristiada fue también una ofensiva del clero contra el gobierno, esta vez, la iglesia no incitó directamente al pueblo para que se lanzara a la lucha, y no redujo ni suspendió el culto, sino que más bien condicionó a los feligreses su estancia dentro de la congregación. El móvil concreto fue la desfanatización,

\footnotetext{
${ }^{27}$ AHSEP, Año 1936, San Felipe del Progreso, Estado de México, Dirección General de Educación Primaria en los Estados y Territorios, Expediente 43/ IV/161(IV-14) /12387 Foja 2.
} 
ya que la nueva ley sobre la educación, que fue promulgada en 1936, era precisa en cuanto a su carácter laico y se pronunciaba decididamente por la enseñanza científica.

El conflicto entre la iglesia y el estado tuvo repercusiones en la escuela. Debido a ello, la SEP modificó su inicial radicalismo, ya que, en algunos lugares del país, la situación se tornó violenta y la vida de los mentores corría riesgo. En la región de estudio, no se reportaron hechos violentos por esta razón, pero si hubo formas de manifestar la inconformidad de la población como la baja en la asistencia, el lento avance al construir el edificio escolar y los anexos o el no cooperar en los trabajos que la escuela necesitaba, el no recibir a los maestros o amenazarlos o no venderles de comer. No obstante, también hubo muestras de adhesión al proyecto federal, entre ellas, el considerar a la escuela como el lugar propicio para atender los asuntos relativos al reparto ejidal y el hecho de que algunas comunidades solicitaran la fundación de una escuela federal. En el distrito de Ixtlahuaca, la Federación se retrasó en la implantación de su proyecto debido al difícil acceso geográfico y a las barreras impuestas por las diferencias lingüísticas. Los procesos de institucionalización y expansión de la escuela rural federal en Ixtlahuaca se presentaron de manera tardía con respecto a otros distritos mexiquenses como Texcoco y Chalco; ${ }^{28}$ estas particularidades se sumaron a los problemas que la educación federal compartía en el país. Aunque los maestros y los inspectores tuvieron que abrirse paso ante una serie de eventualidades que generalmente complicaban su trabajo, es importante señalar que, según el radicalismo de las autoridades educativas en turno, era la reacción de las comunidades que utilizaban diversas estrategias para mostrar su postura ante el "proyecto civilizador" de la Federación. Las reacciones de las comunidades fueron diversas; en algunas localidades, contradictorias, entre las que pueden leerse alianza, negociación, resistencia, indiferencia o franca confrontación. Por ello, la escuela tuvo que luchar para consolidarse como la institución central que orientaría la nueva ideología, exigiendo a la iglesia la liberación de las conciencias y, a los núcleos de poder, la emancipación del pueblo.

Aunque la Federación no logró cumplir las metas que se había propuesto para el distrito de Ixtlahuaca, reorientó la cultura local y la cultura escolar a pesar de los desencuentros que modificaron las posturas iniciales de ambas partes, por lo que podemos considerar que la negociación fue mejor vía de escolarización que la represión. Además, negociar fue un proceso bilateral porque la Federación cedió terreno ante las comunidades, las que a su vez tuvieron que aceptar ciertas condiciones que finalmente les reportaban beneficios como la dotación ejidal y de aguas, la legalización de la tenencia de la tierra, el trazo y construcción de obras de ingeniería como caminos y pozos de agua, la dotación y aplicación de vacunas

\footnotetext{
${ }^{28}$ Véase Alfonseca, Juan (2011), "Estructura y coyuntura. Política, cultura y micropolítica en la institucionalización de la Escuela Rural Federal en los Distritos de Chalco y Texcoco 1922-1940", tesis de doctorado, Universidad Nacional Autónoma de México, México.
} 
y la enseñanza de medidas higiénicas para controlar las epidemias, entre otras. De tal manera que, la mayoría de las comunidades donde se fundaron escuelas federales terminaron por aceptar, o por lo menos tolerar la presencia de la Federación, a cambio de los beneficios recibidos. Al final del periodo de este estudio, algunas localidades apoyaron abiertamente el proyecto civilizador que cambiaba su forma de vida porque vieron que, de alguna manera, representaba el cumplimiento de las promesas de la Revolución, aunque se cumpliesen sólo parcialmente. Como lo sugiere Cecilia Greaves al manifestar que: "Era como si Cárdenas hubiera cumplido con los proyectos de reforma política y social de la Revolución" (Greaves, 2008: 23).

En suma, la entidad mexiquense escolarizó la región entre 1848 y 1940 en un 24\%, mientras que la Federación alfabetizó el 37\% de las comunidades de la región entre 1924 y 1940. Puede considerarse que, al final del cardenismo, ambas redes habían escolarizado, aproximadamente, a 160 comunidades; por lo tanto, alrededor de 100 localidades que constituían el 37\% de las comunidades de la región en 1940, aún se hallaban esperando que la instancia gubernamental las escolarizaría.

\section{Fuentes}

\section{Archivos}

AHSEP Archivo Histórico de la Secretaría de Educación Pública

AHEM Archivo Histórico del Estado de México

AGN Archivo General de la Nación

AMI Archivo Municipal de Ixtlahuaca

AMJ Archivo Municipal de Jocotitlán

AMJ Archivo Municipal de Jiquipilco

AMSFP Archivo Municipal de San Felipe el Progreso

AMSBM Archivo Municipal de San Bartolo Morelos

\section{Bibliografía}

Blanquel, Mario y Hernández, Lorena (1997), Monografía Municipal de San Felipe del Progreso, Gobierno del Estado de México, Toluca.

García, Ramón (1997), Monografía Municipal de San Bartolo Morelos, Gobierno del Estado de México, Toluca.

Greaves, Cecilia (2008), Del radicalismo a la unidad nacional. Una visión de la educación en el México contemporáneo. 1940-1964. El Colegio de México, México.

Hernández, Ricardo (1997), Monografía Municipal de Jiquipilco, Gobierno del Estado de México, Toluca.

Montes de Oca, Elvia (1998), La educación socialista en el Estado de México 1934-1940. Una historia olvidada, El Colegio mexiquense, Zinacantepec.

Olivera, Alicia (1987), Aspectos del conflicto religioso de 1926-1929. Sus antecedentes y consecuencias, Secretaría de Educación Pública, México. 
Palacios, Guillermo (1999), La pluma y el arado. Los intelectuales pedagogos y la construcción sociocultural del "problema campesino" en México, 1932-1934, El Colegio de México, Centro de investigación y docencia económicas, México.

Quintanilla, Susana y Vaughan, Mary (1997), Escuela y sociedad en el periodo cardenista, Fondo de Cultura Económica, México.

Ramírez, Alberto (1997), Monografía municipal de Jocotitlán, Gobierno del Estado de México, Toluca.

Sánchez, Joaquín (1997), Monografía municipal de Ixtlahuaca, Gobierno del Estado de México, Toluca.

Vaughan, Mary (2000), La política cultural en la revolución, maestros, campesinos y escuelas en México 1930-1940, Secretaría de Educación Pública, México.

Yhmoff, Jesús (1979), El municipio de San Felipe del Progreso a través del tiempo. Biblioteca Enciclopédica del Estado de México, Toluca.

\section{Capítulos de libro}

Silva, Yabin (2014), "El cisma que encendió el fuego: la iglesia católica apostólica mexicana y la guerra cristera" en Ramírez Padilla y Marco Fabrizio (coord.), La guerra de religión en México (1926-1929), Palabra de Clío, historiadores mexicanos, México, pp. 79-102.

Vaughan, Mary (2002), "La Historia de la educación y las regiones en México: cómo leer los informes de los inspectores escolares" en Alicia Civera, Carlos Escalante y Luz Galván (coord.), Debates y desafíos de la historia de la educación en México. Zinacantepec, Estado de México, El Colegio Mexiquense, A.C.; Instituto Superior de Ciencias de la Educación del Estado de México, pp. 39-66.

Zarco, Celia (1996), "La escuela socialista en Ixtlahuaca, México", en Memoria Sexto Encuentro Nacional y Segundo Internacional de Historia de la Educación, Guadalajara, Secretaría de Educación Pública del Gobierno del Estado de Jalisco, v. III, pp. 1-10.

\section{Artículos de publicación periódica}

Herrera, Lucino y Rodríguez, Francisco (1997), "El pensamiento educativo en el México posrevolucionario", ANUIES, Revista de Educación Superior, núm. 103, julio-septiembre, pp. 1-16.

\section{Tesis}

Alfonseca, Juan (2011), "Estructura y coyuntura. Política, cultura y micropolítica en la institucionalización de la Escuela Rural Federal en los Distritos de Chalco y Texcoco 1922-1940", tesis de doctorado, Universidad Nacional Autónoma de México, México.

Escalante, Carlos (2008), "Entre la apropiación y la resistencia mazahuas. Cultura escolar y cultura local (1879-1940)", tesis de doctorado, Departamento de Investigaciones Educativas, México.

Zarco, Celia (2014), "La escolarización rural federal en el Distrito de Ixtlahuaca 1922-1940", tesis de maestría, Instituto Superior de Ciencias de la Educación del Estado de México, México.

\section{Documentos}

Dirección de Agricultura y Ganadería del Gobierno del Estado de México (1958), Catálogo: Los ejidos del Estado de México, Toluca.

Instituto Nacional de Estadística, Geografía e Informática. INEGI (1940), Censo histórico del Estado de México, Toluca.

Villada, José (1902), Memoria que el ciudadano José Vicente Villada presenta a la Honorable Legislatura del Estado de México cerca de sus actos como Gobernador Constitucional durante el cuatrienio de 1897 a 1901. Oficina Tipográfica del Gobierno, Toluca. 


\section{Publicaciones electrónicas}

Ávila, Olimpia (2015), "SEP: el origen de una institución" Excélsior, http://www.excelsior.com.mx/nacional/2015/10/22/1052679, (Consultado el 24 de enero de 2020).

Granja, Josefina (2010), "Procesos de escolarización en los inicios del siglo XX. La instrucción rudimentaria en México", Perfiles educativos vol. 32 no. 129, México http://www.scielo.org.mx/scielo. php? script=sci arttext\&pid=S0185-26982010000300005, (Consultado el 5 de julio de 2016).

Meyer, Jean (2005), "La iglesia católica en México 1929-1965", CIDE No. 30. https://cide.repositorioinstitucional.mx/jspui/bitstream/1011/169/1/000060392_documento.pdf (Consultado el 10 de diciembre de 2019).

Silva, Marduk (2019), "El primer trabajo civilizador de la SEP en el año de 1923”, Juárez a diario, https:/L www.juarezadiario.com/plumas/el-primer-trabajo-civilizador-de-la-sep-en-el-ano-de-1923/, (Consultado el 24 de enero de 2020). 